\title{
Mechanical and Thermal Properties of Individual Phases Formed in Sintered Tungsten-Steel Composites
}

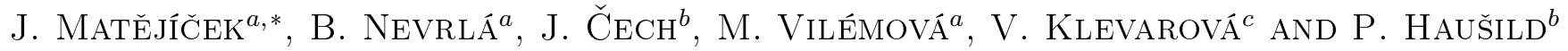 \\ ${ }^{a}$ Institute of Plasma Physics, Za Slovankou 3, 18200 Praha, Czech Republic \\ ${ }^{b}$ Czech Technical University in Prague, Faculty of Nuclear Sciences and Physical Engineering, \\ Trojanova 13, 12000 Praha, Czech Republic \\ ${ }^{c}$ Charles University, Faculty of Mathematics and Physics, Ke Karlovu 3, 12116 Praha, Czech Republic
}

\begin{abstract}
Tungsten is a prime candidate material for plasma facing components in fusion devices, thanks to its advantageous properties with respect to interaction with hot plasma. For its bonding to the supporting structure, composites and graded layers can be used for the reduction of stress concentration at the interface. When tungsten and steel are processed at elevated temperatures, e.g. hot pressing or spark plasma sintering, intermetallic phases may form and their presence and properties will affect the properties of the composite. In this work, mechanical and thermal properties of the individual phases, i.e. steel, tungsten and $\mathrm{Fe}-\mathrm{W}$ intermetallics are investigated. Mechanical properties were determined by instrumented indentation. Thermal conductivity was determined by the xenon flash method on a range of samples with varying composition, from which the conductivities of each constituent were estimated. The results can be used for the optimization of compositional profiles and processing conditions for manufacturing of plasma facing components.
\end{abstract}

DOI: $10.12693 /$ APhysPolA.128.718

PACS: $62.20 .-\mathrm{x}, 65.40 .-\mathrm{b}$

\section{Introduction}

Modern engineering applications pose ever increasing requirements on the materials used. Some of these may not be fulfilled by single materials - therefore, composites and functionally graded materials (FGMs) are being developed and used. An example of such application with extreme conditions is a fusion device. Its plasma facing components have to withstand high heat and particle fluxes from the hot plasma, including steady-state loading as well as thermal shocks, and transfer the heat to the cooling system. In particular, for the next step fusion device - DEMO - plasma facing components made of tungsten and steel are foreseen. Tungsten will be the plasma facing armor and steel will serve for the support structure and cooling system [1]. An FGM interlayer may reduce the stress concentration between these two materials, compared to a sharp interface [2]. Depending on the processing technique, intermetallic compounds such as $\mathrm{Fe}_{2} \mathrm{~W}$ and $\mathrm{Fe}_{7} \mathrm{~W}_{6}$ may form [3]. For design considerations, the properties of all constituents need to be known; these are the subject of this paper.

\section{Experimental}

Tungsten-steel composites of various compositions (including pure tungsten and pure steel) were prepared by spark plasma sintering in an SPS 10-4 machine (Thermal Technology, USA). Tungsten (Osram Sylvania, USA) and P91 steel (Karlsruhe Institute of Technology, Germany), sieved to $20 \mu \mathrm{m}$ size were used. The powders with specific

*corresponding author; e-mail: jmatejic@ipp.cas.cz volume ratios were manually mixed, placed in a graphite die lined with a graphite foil, manually pre-pressed and sintered in the SPS machine. Composition of the samples and processing conditions are listed in Table I. The samples were sintered in a pulsed current regime, in $\mathrm{He}$ atmosphere at $50 \mathrm{~Pa}$. The sintering temperature was reached with a heating rate of $100{ }^{\circ} \mathrm{C} / \mathrm{min}$; cooling rate was also $100^{\circ} \mathrm{C} / \mathrm{min}$ down to about $800^{\circ} \mathrm{C}$, when a natural cooldown ensued. For the structure observations and determination of volumetric ratio of the phases, SEM images (EVO MA15, Carl Zeiss SMT, Germany) of polished cross-sections were used. While the intermetallic phase is generally an undesired phase, several samples were prepared specifically at conditions suitable for its formation, to have a significant volume available for the measurement of its properties. The intermetallic phase was identified by X-ray diffraction (D8 Discover, Bruker AXS, Germany) as $\mathrm{Fe}_{7} \mathrm{~W}_{6}$; this was verified by a fullpattern Rietveld refinement.

Mechanical properties were determined by instrumented indentation on a CSM NHT instrument (Anton Paar TriTec, Switzerland). The Young modulus and hardness were obtained by the Oliver-Pharr technique [4] using the Berkovich indenter and maximum load of $1 \mathrm{mN}$ (corresponding to the depth of indentation less than $100 \mathrm{~nm}$ ). Yield stress and hardening exponent were estimated by the Tabor relations using a spherical diamond indenter (tip radius $20 \mu \mathrm{m}$ ) and stepwise increasing loads up to $200 \mathrm{mN}$ [5]. Yield stress value was determined by extrapolation of the representative stress - representative strain curves to 0.002 plastic strain [6].

Thermal conductivities were determined by the xenon flash method, using an FL-3000 instrument (Anter, USA) at temperatures of 100,250 , and $400{ }^{\circ} \mathrm{C}$. Since the 
$\mathrm{Fe}_{7} \mathrm{~W}_{6}$ phase was not available in a pure form, thermal conductivities of all 8 samples with different compositions were used in the evaluation. The following models for a composite thermal conductivity were used: arithmetic mean (parallel model), harmonic mean (series model), geometric mean, Bruggeman-Landauer self-consistent approximation (effective medium theory),
Budiansky model and Hashin-Shtrikman upper and lower bounds [7-9]. For each model, conductivities of the three phases were calculated at the three different temperatures using the least squares method, i.e. minimizing the sum of squares of differences between measured and calculated composite conductivities for the eight samples.

TABLE I

Processing conditions, composition and thermal conductivity of the SPS composites. Typical accuracy of the thermal conductivity measurement is $3-5 \%$.

\begin{tabular}{c|c|c|c|c|c|c|c|c|c|c}
\hline \hline & P91:W & temp. & pressure & time & $\mathrm{W}$ & $\mathrm{P} 91$ & \multicolumn{2}{|c|}{$\mathrm{Fe}_{7} \mathrm{~W}_{6}$} & \multicolumn{3}{|c}{ thermal cond. [W/(m K)] } \\
\hline no. & {$[\mathrm{vol} \%]$} & {$\left[{ }^{\circ} \mathrm{C}\right]$} & {$[\mathrm{MPa}]$} & {$[\mathrm{min}]$} & {$[\mathrm{vol} \%]$} & {$[\mathrm{vol} \%]$} & {$[\mathrm{vol} \%]$} & $100{ }^{\circ} \mathrm{C}$ & $250{ }^{\circ} \mathrm{C}$ & $400{ }^{\circ} \mathrm{C}$ \\
\hline 1 & $50: 50$ & 1100 & 80 & 2 & 44 & 40 & 15 & 51 & 44 & 46 \\
2 & $25: 75$ & 1100 & 80 & 2 & 65 & 23 & 12 & 59 & 53 & 49 \\
3 & $75: 25$ & 1100 & 80 & 2 & 16 & 76 & 7 & 33 & 34 & 34 \\
4 & $25: 75$ & 1300 & 80 & 2 & 50 & 7 & 43 & 51 & 47 & 44 \\
5 & $25: 75$ & 1400 & 80 & 2 & 42 & 0 & 58 & 41 & 40 & 39 \\
6 & $47: 53$ & 1400 & 80 & 30 & 15 & 0 & 85 & 20 & 23 & 24 \\
7 & $\mathrm{~W}$ & 2100 & 80 & 2 & 100 & 0 & 0 & 157 & 136 & 122 \\
8 & $\mathrm{P} 91$ & 1100 & 80 & 2 & 0 & 100 & 0 & 31 & 31 & 28
\end{tabular}

\section{Results and discussion}

Phase composition of the individual samples is presented in Table I. A representative structure of the composite with a significant amount of $\mathrm{Fe}_{7} \mathrm{~W}_{6}$ is shown in Fig. 1. All the composites had isotropic structure with negligible amount of porosity, while the contiguity of each phase naturally changed with its content. Therefore, conductivity models not involving any geometrical factors were considered.

Mechanical properties of the phases.

TABLE II

\begin{tabular}{c|c|c|c|c}
\hline \hline phase & $E_{I T}[\mathrm{GPa}]$ & $H_{I T}[\mathrm{MPa}]$ & $R_{p} 0.2[\mathrm{MPa}]$ & hardening exponent \\
\hline P91 steel & $205 \pm 19$ & $4262 \pm 227$ & $682 \pm 208$ & 0.17 \\
tungsten & $402 \pm 40$ & $9745 \pm 1523$ & $794 \pm 71$ & 0.23 \\
$\mathrm{Fe}_{7} \mathrm{~W}_{6}$ & $356 \pm 16$ & $22339 \pm 1311$ & $1791 \pm 397$ & 0.25
\end{tabular}

Thermal conductivities of individual phases calculated according to different models.

TABLE III

\begin{tabular}{|c|c|c|c|c|c|c|c|c|c|c|c|c|}
\hline & \multicolumn{3}{|c|}{ arithmetic mean } & \multicolumn{3}{|c|}{ harmonic mean } & \multicolumn{3}{|c|}{ geometric mean } & \multicolumn{3}{|c|}{ EMT } \\
\hline & $100^{\circ} \mathrm{C}$ & $250{ }^{\circ} \mathrm{C}$ & $400^{\circ} \mathrm{C}$ & $100^{\circ} \mathrm{C}$ & $250^{\circ} \mathrm{C}$ & $400^{\circ} \mathrm{C}$ & $100^{\circ} \mathrm{C}$ & $250^{\circ} \mathrm{C}$ & $400^{\circ} \mathrm{C}$ & $100^{\circ} \mathrm{C}$ & $250^{\circ} \mathrm{C}$ & $400^{\circ} \mathrm{C}$ \\
\hline $\mathrm{W}$ & 129 & 112 & 102 & 157 & 136 & 122 & 153 & 132 & 118 & 121 & 103 & 95 \\
\hline P91 & 19 & 20 & 20 & 31 & 29 & 28 & 23 & 23 & 23 & 28 & 28 & 27 \\
\hline $\mathrm{Fe}_{7} \mathrm{~W}_{6}$ & -15 & -7 & -2 & 26 & 25 & 25 & 14 & 15 & 16 & 14 & 16 & 17 \\
\hline \multirow[t]{3}{*}{$\mathrm{S}$} & \multicolumn{3}{|c|}{4902} & \multicolumn{3}{|c|}{318} & \multicolumn{3}{|c|}{994} & \multicolumn{3}{|c|}{3941} \\
\hline & \multicolumn{3}{|c|}{ Budiansky } & \multicolumn{3}{|c|}{ H-S upper } & \multicolumn{3}{|c|}{ H-S lower } & \multicolumn{3}{|c|}{ ref } \\
\hline & $100^{\circ} \mathrm{C}$ & $250^{\circ} \mathrm{C}$ & $400^{\circ} \mathrm{C}$ & $100^{\circ} \mathrm{C}$ & $250^{\circ} \mathrm{C}$ & $400^{\circ} \mathrm{C}$ & $100^{\circ} \mathrm{C}$ & $250^{\circ} \mathrm{C}$ & $400^{\circ} \mathrm{C}$ & \multicolumn{3}{|c|}{ RT } \\
\hline W & 153 & 128 & 115 & 140 & 121 & 109 & 156 & 134 & 120 & \multicolumn{3}{|c|}{$163[12]$} \\
\hline P91 & 29 & 29 & 27 & 20 & 21 & 21 & 27 & 26 & 24 & \multicolumn{3}{|c|}{33 [13] } \\
\hline $\mathrm{Fe}_{7} \mathrm{~W}_{6}$ & 18 & 20 & 20 & -5 & 1 & 5 & 16 & 16 & 18 & & & \\
\hline S & \multicolumn{3}{|c|}{840} & \multicolumn{3}{|c|}{2908} & \multicolumn{3}{|c|}{549} & & & \\
\hline
\end{tabular}




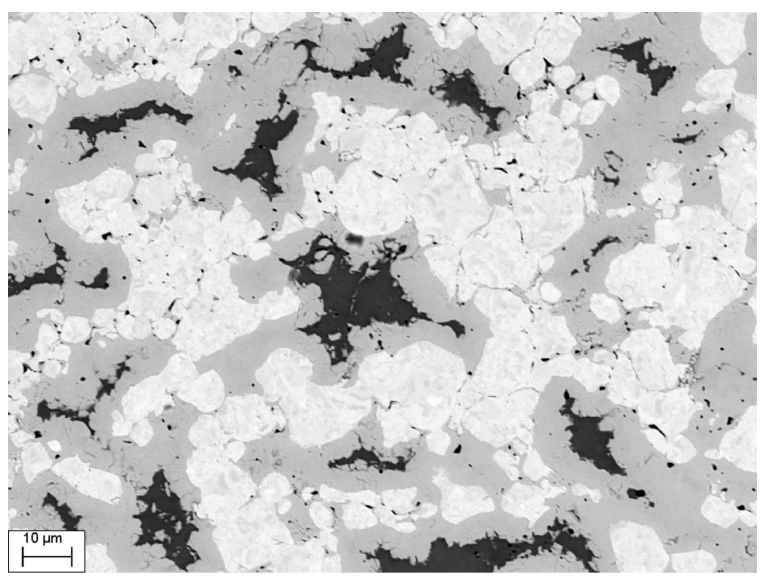

Fig. 1. Structure of the tungsten-steel composite with a significant amount of $\mathrm{Fe}_{7} \mathrm{~W}_{6}$ (SEM image in a backscattered electron mode; dark phase $=$ steel, grey phase $=\mathrm{Fe}_{7} \mathrm{~W}_{6}$, light phase $=$ tungsten; sample no. 4 from Table I).

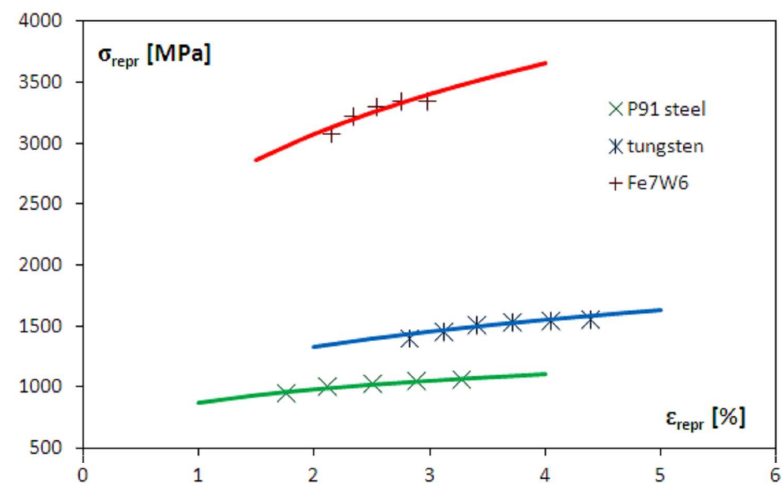

Fig. 2. Representative stress-strain curves of the phases.

Mechanical properties determined from the spherical indentation experiments, are shown in Table II. The $\mathrm{Fe}_{7} \mathrm{~W}_{6}$ phase has much higher yield strength than both tungsten and steel, whereas the hardening exponents are all similar. Parts of the indentation stress-strain curves are shown in Fig. 2. Indentation data at the lowest loads were excluded, to avoid the influence of surface roughness and imperfection of the indenter shape. At high loads, the presence of the other phases in the vicinity of the indent did not allow to properly measure the properties of individual phases.

Thermal conductivities of the phases, calculated according to different models, are listed in Table III. Suitability of the models was compared using the sum of squares of differences between calculated and experimental composite conductivity values for all 24 measurements (denoted $S$ ). From this comparison, the harmonic mean (corresponding to the series model) appears the best, closely followed by the Hashin-Shtrikman lower bound and the Budiansky model. Two models yielded unrealistic values for the $\mathrm{Fe}_{7} \mathrm{~W}_{6}$ phase, therefore are deemed unsuitable for this system. Nevertheless, the values predicted by all the models were fairly close to each other, confirming the feasibility of this approach. The values for $\mathrm{W}$ and $\mathrm{P} 91$ steel at $100{ }^{\circ} \mathrm{C}$ are very close to room temperature literature values for bulk materials. Thermal conductivity of $\mathrm{W}$ is much higher than that of steel and $\mathrm{Fe}_{7} \mathrm{~W}_{6}$, the latter being the lowest. Also, thermal conductivity of $\mathrm{W}$ decreases quite noticeably with temperature, while it remains nearly constant for the other two phases. In connection with these results, few general points from the comprehensive treatment by Terada et al. [10] may be worth mentioning. Pure metals generally have higher conductivities with weaker temperature dependence than intermetallic compounds. While the first statement holds true for our results, the latter does not. Also, according to [10], thermal conductivity vs. composition in binary compounds generally has a maximum at stoichiometry, while the ordered intermetallic compounds should have higher conductivity than corresponding solid solutions. According to the $\mathrm{Fe}-\mathrm{W}$ phase diagram [11], $\mathrm{Fe}_{7} \mathrm{~W}_{6}$, exists in the $40.5-$ 44.5 at. $\% \mathrm{~W}$ range. Moreover, the P91 steel contains about $9 \mathrm{wt} \% \mathrm{Cr}$, thus the intermetallic phase should not be regarded as pure $\mathrm{Fe}_{7} \mathrm{~W}_{6}$. EDS microanalysis on several points yielded the following composition (at.\%): W 40.6, Fe 54.1, Cr 5.3. Therefore, one can conclude that the thermal properties might vary with the processing conditions.

\section{Conclusions}

Mechanical and thermal properties, namely yield strength, hardening exponent and thermal conductivity, of the individual phases in spark plasma sintered tungsten-steel composites were determined. Of particular importance is the $\mathrm{Fe}_{7} \mathrm{~W}_{6}$ phase, as to our knowledge, no such data were available until now. These are important for the design of plasma facing components in future fusion devices and for the selection of processing techniques. While the Young modulus of $\mathrm{Fe}_{7} \mathrm{~W}_{6}$ lies between those of steel and tungsten, its yield strength is much higher. On the other hand, its thermal conductivity is the lowest of the three phases. Since high thermal conductivity is required for the plasma facing parts, its presence should be regarded as undesirable. Even if the $\mathrm{Fe}_{7} \mathrm{~W}_{6}$ formation is eliminated or minimized at the processing stage (e.g. by using lower temperatures and/or short processing times), it may still form due to long-term exposure to elevated temperatures in service.

\section{Acknowledgments}

Support from the Czech Science Foundation (grant no. P108/12/1872) and CTU in Prague (grant no. SGS13/222/OHK4/3T/14) is acknowledged. Consultation with Dr. Willi Pabst regarding the thermal conductivity models is also appreciated. 


\section{References}

[1] J. Matějíček, Acta Polytechn. 53, 197 (2013).

[2] T. Weber, J. Aktaa, Fusion Eng. Des. 86, 220 (2011).

[3] J. Matějíček, B. Nevrlá, M. Vilémová, H. Boldyryeva, Nukleonika 60, 267, 2015.

[4] W.C. Oliver, G.M. Pharr, J. Mater. Res. 19, 3 (2004).

[5] P. Haušild, A. Materna, J. Nohava, Mater. Des. 37, 373 (2012).

[6] J. Čech, P. Haušild, J. Nohava, J. Matějíček, in: Proc. JuveMatter 2014, Nečtiny, Ed.: J. Kunz, Čské vysoké učení technické v Praze, Praha 2014, p. 76.

[7] L. Gong, Y. Wang, X. Cheng, R. Zhang, H. Zhang, Int. J. Heat Mass Transf. 68, 295 (2014).
[8] R.C. Progelhof, J.L. Throne, R.R. Ruetsch, Polym. Eng. Sci. 16, 615 (1976).

[9] W. Pabst, E. Gregorová, J. Phys. Conf. Series 395, 012021 (2012).

[10] Y. Terada, K. Ohkubo, T. Mohri, T. Suzuki, Mater. Trans. 43, 3167 (2002).

[11] H. Okamoto, Desk Handbook: Phase Diagrams for Binary Alloys, ASM International, Materials Park 2000.

[12] MatWeb: Online Materials Information Resource.

[13] P91-T91 Material Data Sheet, Thyssen-Krupp 2011. 